\title{
NON-POLYMERIC CHEMICALS OR ADDITIVES ASSOCIATED WITH MICROPLASTIC PARTICULATE FRACTION IN A TREATED URBAN EFFLUENT
}

\author{
JAVIER BAYO, SONIA OLMOS \& JOAQUÍN LÓPEZ-CASTELLANOS \\ Department of Chemical and Environmental Engineering, Technical University of Cartagena, Spain
}

\begin{abstract}
The presence of microplastics in freshwater environments is of emerging concern, because they have been ubiquitously detected. Different adverse effects have been described in ingesting organisms: physical damage due to the plastic particles themselves, leaching of constituent monomers, the potential transport of organic and inorganic pollutants, and leaching of additives used in the manufacturing and polymerization of plastic products. In this last case, especially when additives are not chemically bound to the polymer structure, may be leached out into the aquatic environment. This paper deals with the role of wastewater treatment plants as sources of additives associated to particulate forms. A $9.0 \%$ of particulate fraction was a source of plastic additives, such as antioxidants, lubricants, corrosion inhibitors, plasticizers, adhesives, heat stabilizers or flame retardants, among others. The main plastic additives found in the wastewater samples were $\mathrm{Zn} / \mathrm{Ca}$ PVC stabilizer, Methyl Tin Mercaptide (MTM), Ethoxylated Tallow Alkyl Amine (ETAA), Methyl Alkyl Imidazoline Sodium Salts (MAISS), Butyl Ricinoleate (BR), Di-o-benzamido diphenyl disulfide (DBD), RTV-730 and Molybdenum-Zinc Oxygen Complex (MZO Complex). There was a statistically significant removal of all of them after the wastewater treatment process, accounting for a $91.14 \%$, although some of them proved to disappear in the biological reactor or even in the primary clarifier.

Keywords: additives, microplastics, heat stabilizers, surfactants, plasticizers, corrosion inhibitors.
\end{abstract}

\section{INTRODUCTION}

The global annual production of plastics was around 335 million tonnes for 2016, with a approximately an $19 \%$ of them produced in Europe, where $70 \%$ of the demand is concentrated in six countries; i.e., Germany (24.5\%), Italy (14.2\%), France (9.6\%), Spain (7.7\%), UK (7.5\%), and Poland (6.3\%) [1]. Plastics are made of polymers, long and flexible chain molecules formed after reaction of smaller ones called monomers [2], and whose properties are adjusted by means of additives. These additives; i.e., lubricants, fire retardants, emulsifiers, plasticizers, adhesives, and so on, may leach from plastic materials, with environmental effects not easy to assess [3].

The fragmentation of large plastic debris into smaller ones takes place in the environment, due to physical, biological and chemical mechanisms, being chemical and mechanical weathering the most important ones, originating the term "microplastics", used for plastics smaller than $5 \mathrm{~mm}[4]$.

This paper describes the behaviour of particulate forms associated to additives isolated in different processes within a wastewater treatment plants (WWTP). The monitoring study was carried out between September 2016 and October 2017, with $9.0 \%$ of particulate fraction being a major source of plastic additives. It is well known that these additives can leak out during the life cycle of the product, being potentially harmful to wildlife. 


\section{MATERIALS AND METHODS}

\subsection{Sample processing}

A total of 173.695 L of water were processed for this study, carried out from September 2016 to October 2017. Samples were collected in four sampling points; i.e., influent, primary clarifier, biological reactor, and effluent, from an urban WWTP located in Cartagena, a Mediterranean city located in the Southeast of Spain. This WWTP has been previously described in Bayo et al. [4]. Total wastewater volume was distributed as follows: $7.9 \%$ from the influent, $7.6 \%$ from the primary clarifier, $38.0 \%$ from the biological reactor, and $46.5 \%$ from the effluent, with $55.14 \%$ collected in the morning $(9: 00 \mathrm{~h})$, and $44.86 \%$ in the evening $(15: 00 \mathrm{~h})$. All samples were collected in glass containers, in order to avoid additional contamination, and kept refrigerated at $4^{\circ} \mathrm{C}$ on arrival to the laboratory. Microparticles were extracted from wastewater samples by means of a concentrate sodium chloride solution $\left[\mathrm{NaCl} ; 120 \mathrm{~g} \cdot \mathrm{l}^{-1}\right]$, as previously indicated by Bayo et al. [5], resulting in a supernatant with floating particles, that were filtered through a Whatman filter paper $(0.45 \mu \mathrm{m})$. After washing this filter with bi-distilled water and drying on stove, microparticles were processed by microscopic and FTIR analyses.

\subsection{Microparticles analyses}

Microscopic analyses were carried out with an Olympus SZ61 trinocular microscope (Edmund Optics Spain, Canary Islands), providing a superior image quality with a $10^{\circ}$ convergence angle at a working distance of $110 \mathrm{~mm}$, magnification range from $6.7 \mathrm{x}$ to $45 \mathrm{x}$ and LED lighting. This trinocular microscope was coupled with an Olympus Altra 20 high resolution digital camera, with a maximum resolution of $1596 \times 1196$ pixels, 10 bits per color channel, 7.5 frames per second at full resolution, and $0.1 \mathrm{~ms}$ to $1 \mathrm{~s}$ exposure time. The infrared spectra were acquired with a Thermo Nicolet 5700 Fourier transformed infrared (FTIR) spectrometer (Thermo Nicolet Analytical Instruments, Madison, WI, USA), provided with a deuterated triglycine sulfate (DTGS) detector and $\mathrm{KBr}$ detector. The spectra collected were an average of 20 scans with a resolution of $16 \mathrm{~cm}^{-1}$ in the range of $4000-400 \mathrm{~cm}^{-1}$. Spectra were controlled and evaluated by the OMNIC software package, by means of different reference spectra databases, where peak maxima were manually determined after examination of absorbance values.

\section{RESULTS AND DISCUSSION}

\subsection{General results}

A total of 720 microparticles were analyzed in this study, all of them smaller or equal than 5 $\mathrm{mm}$ in diameter. After examination through the stereo microscope, each identified particle was subjected to infrared analysis. As already mentioned, the objective was to differentiate microplastics from other types of particles, thus avoiding false positives that, in our opinion, other authors have been able to include in their counts, by using visualization through an optical microscope as the only method for microplastic identification [6].

Thus, our study differentiates among microplastic particles, additives or non-polymeric chemicals, as materials used in the manufacture of plastic products, and other substances of less interest for this analysis, i.e., remnant of soap, glycerine, talc, cellulose or chipboard. 
Out of all analyzed particles, $41.7 \%$ were found to be microplastic while $9.0 \%$ were identified as plastic additives, such as antioxidants, lubricants, antimicrobials, plasticizers, emulsifiers, adhesives, heat stabilizers, etc. Approximately $4 \%$ of the weight of plastic is its additives [7]. It is well known that these additives can leach during the life cycle of the product, exerting toxicity in the aquatic environment [8].

For all these reasons, a separate study of these chemicals associated to microplastic particulate fraction would be interesting, giving specific concordance in the infrared spectroscopy analysis. Fig. 1 shows the evolution of all additives identified in this research. The average concentrations of particulate forms per litre of sampled wastewater were $2.13 \pm 0.57 ; 1.26 \pm 0.37 ; 0.33 \pm 0.12 ;$ and $0.19 \pm 0.07$, for the influent, primary clarifier, secondary clarifier, and effluent, respectively. These outcomes proved a statistically significant removal of these chemicals through the WWTP, accounting for a $91.2 \%$ between influent and effluent $(t$-test $=3.206, p<0.01)$. The decrease was also significant between the influent and the biological reactor $(84.6 \%$; t-test $=3.063, p<0.01)$, although it was not between influent and primary clarifier $(41.1 \%$; t-test $=1.480, p=0.163)$.

These results may indicate a clear influence of biological reactor in the removal of these particulate additives whether they were degraded by biological processes or transferred to the secondary sludge. Moreover, that was not the only evidence supporting our hypothesis, because there also was a statistically significant decrease from primary clarifier to the biological reactor $(73.9 \%$, $t$-test $=2,587, p<0.05)$, but not between biological reactor and final effluent $(42.5 \%, t$-test $=0.512, p=0.617)$.

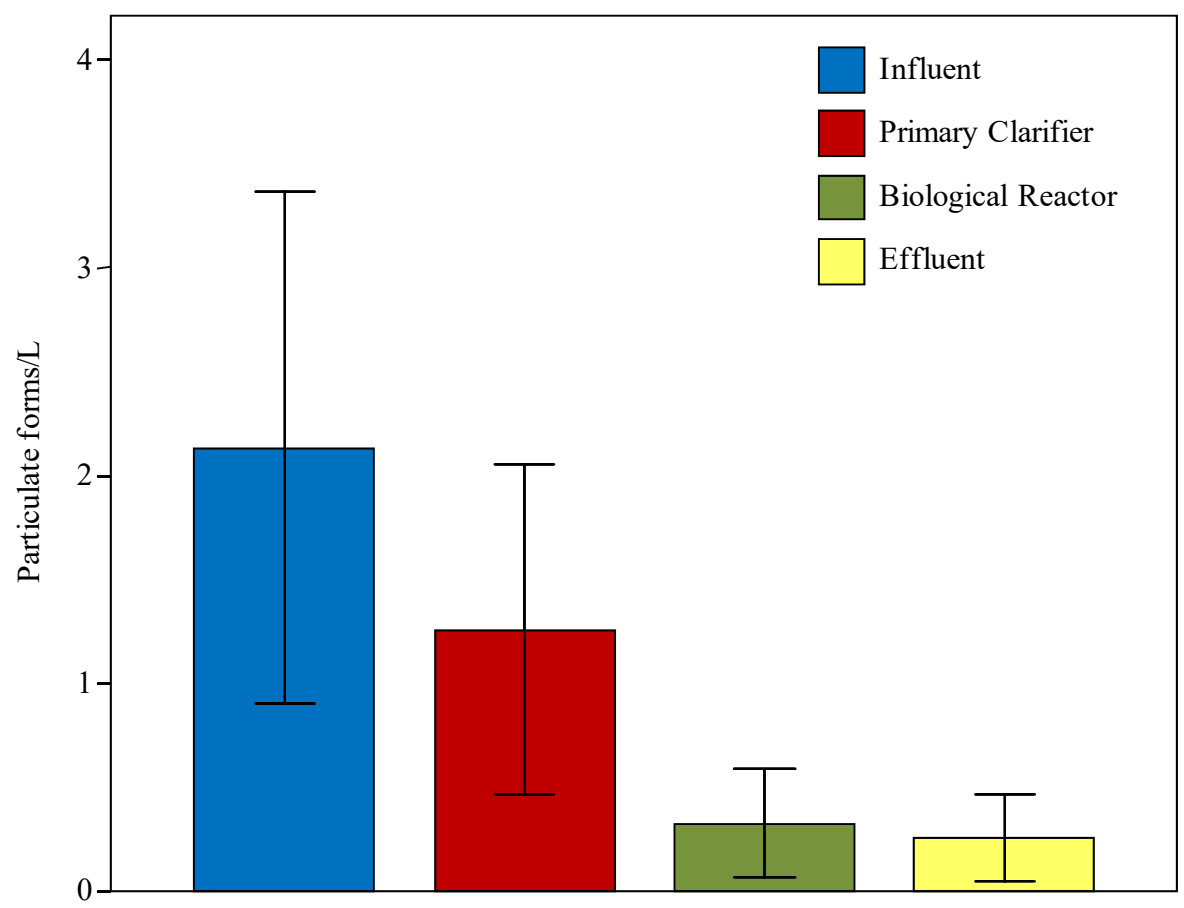

Figure 1: Mean concentration of total additives isolated in particulate forms through the wastewater treatment plant (error bars represent $95.00 \%$ confidence interval). 


\subsection{Presence and evolution of different plastic additives}

\subsubsection{Heat stabilizers}

Two different heat stabilizers were isolated in wastewater samples; i.e., $\mathrm{Zn} / \mathrm{Ca} \mathrm{PVC}$ stabilizer, and Methyl Tin Mercaptide (MTM). It is well known that one of the main drawbacks or limitation for the use of polyvinyl chloride (PVC) is its low thermal stability. For that reason, proper stabilizers must be incorporated in order to rein back the polymer degradation during thermal processing, avoiding the release of hydrogen chloride $(\mathrm{HCl})$, which favours its decomposition [9].

Lead compounds have been used for years, as a cost-effective form of PVC stabilizer, although their use has decreased as a result of the voluntary sustainable development programme of the European PVC industry [10]. In this sense, although zinc soaps are efficient stabilizers, the product zinc chloride $\left(\mathrm{ZnCl}_{2}\right)$ accelerates dehydrochlorination of PVC. For that reason, a synergistic effect is used by combining it with alkaline earth carboxylates, i.e., calcium chloride $\left(\mathrm{CaCl}_{2}\right)$ [11].

$\mathrm{Zn} / \mathrm{Ca} \mathrm{PVC}$ stabilizer, also named as $\mathrm{Zn} / \mathrm{Ca}$ soap, is especially used for outdoor window and low foaming PVC profiles, giving good plasticizing properties, colour maintenance and weathering resistance [12]. In this research, this stabilizer has been detected in particulate forms in the influent, primary clarifier, biological reactor, and effluent, with a statistically significant correlation between influent and effluent $(r=0.743, p<0.01)$, and an average removal of $85.2 \%$.

The other heat stabilizer isolated in wastewater samples was Methyl Tin Mercaptide (MTM), an excellent PVC heat stabilizer, which is effective for rolling, extrusion, and injection moulding of hard PVC. It is also applicable to food packing, with a maximal dosage of $2 \%$, plastic doors and water pipes, giving good colour prevention and transparency, with an acute toxicity accident reported in a plastic company in China [13]. Despite its use in food packing, the release of MTM to natural systems poses considerable environmental damage and health risk [14], [15].

The organotin compounds, in addition to their toxicity, persist in the environment for long duration due to their high bioaccumulation factor, so industrial effluents containing these chemicals have to be treated by physicochemical methods, as the biological treatment processes are ineffective [16]. Particulate forms of MTM displayed average concentrations in the influent and effluent of $0.18 / \mathrm{L}$ and $0.01 / \mathrm{L}$, respectively, with a positive and statistically significant correlation $(r=0.981, p<0.001)$, and with an average removal of $89.2 \%$. Fig. 2 presents the evolution of particulate forms of both additives in the wastewater treatment plant.

$\mathrm{Zn} / \mathrm{Ca}$ soap and MTM are referenced as the most commonly PVC stabilizers used all over the world $[17,18]$. Maybe for that reason, both additives displayed a statistically significant positive correlation in this study $(r=0.748, p<0.01)$. A comparison of the FTIR spectra for a particulate form of MTM and the pure component are depicted in Fig. 3. Characteristic distinctive bands for $\mathrm{CH}$ and $\mathrm{CH}_{2}$ groups are shown between 2930 and $2850 \mathrm{~cm}^{-1}$ wavelengths, due to asymmetric vibration of $\mathrm{CH}_{2}$ [19], near $1710 \mathrm{~cm}^{-1}$ because of $\mathrm{C}=\mathrm{O}$ stretching [20], and $710-570 \mathrm{~cm}^{-1}$ for sulphur-carbon stretch [21].

\subsubsection{Surfactants or emulsifiers}

Two different surfactants were detected in the urban effluent; i.e., Ethoxylated Tallow Alkyl Amine (ETAA), and Methyl Alkyl Imidazoline Sodium Salts (MAISS).

The Ethoxylated Tallow Alkyl Amine (ETAA) is a non-ionic surfactant or emulsifier used for household, cosmetic and industrial purposes, including different applications such as 
detergent powders or liquids, fabric softeners, corrosion inhibitors, textile auxiliaries [22], and even in the pesticide industry, reducing the effective dose 50 (ED50) as compared to other common surfactants [23]. Since the dramatic rise of oil prices during the $80 \mathrm{~s}$, surfactant based on natural fats and oils gained in importance all over the world, especially in the detergents industry. Because of its wide use, the presence of particulate forms with this additive could be related to both urban and agronomic uses in our area. In our study, it can be observed a clear decrease from the influent to the biological reactor; i.e., $83.2 \%$, totally disappearing in the final effluent.

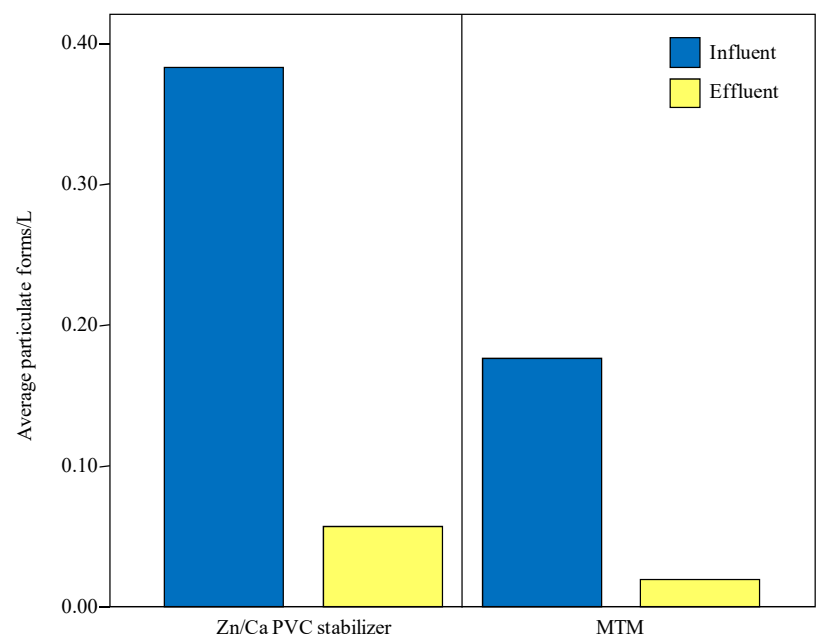

Figure 2: Zn/Ca PVC stabilizer and MTM evolution through the WWTP.

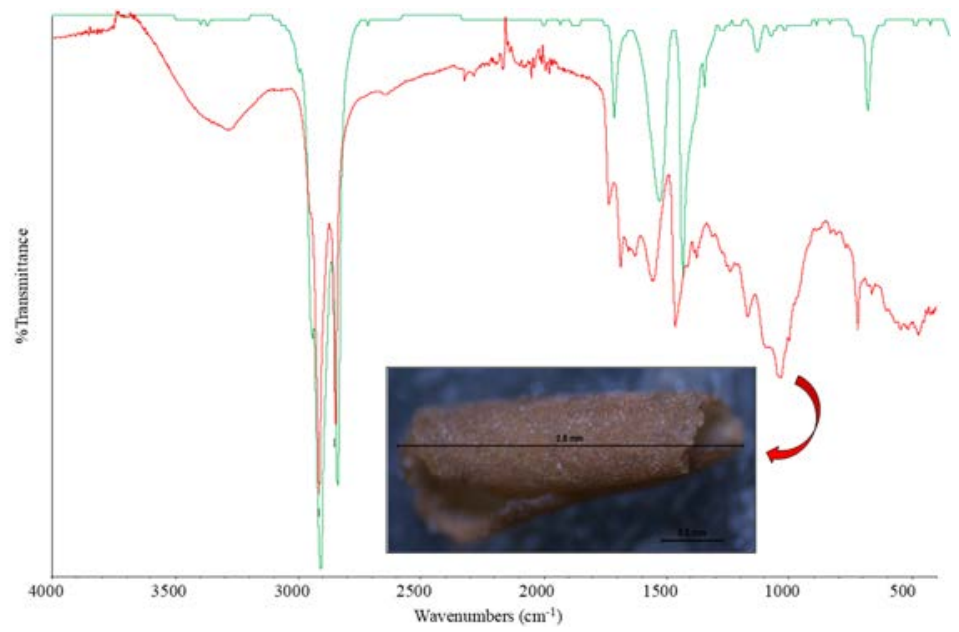

Figure 3: TIR spectra for pure Methyl Tin Mercaptide (MTM) (green line) and for a particulate form containing this additive in the wastewater influent to the plant (Match: 91.53\%; Library: Polymer Additives and Plasticizers). 


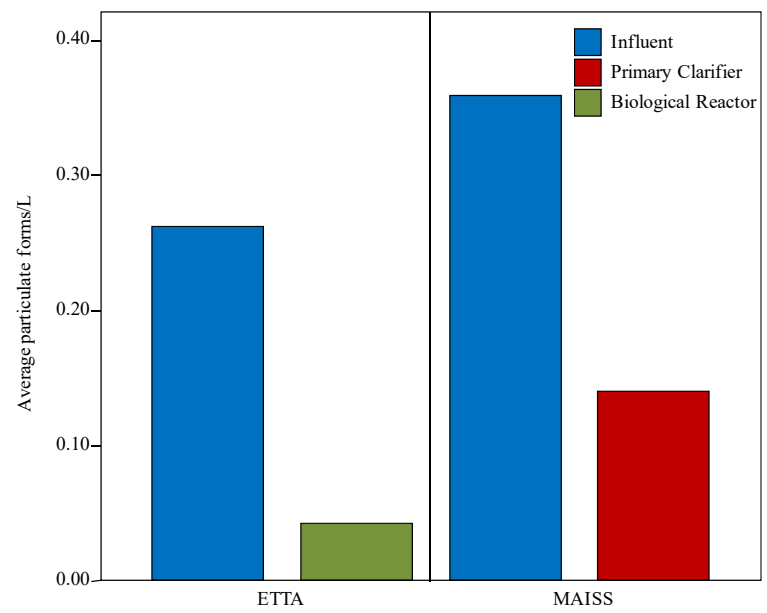

Figure 4: ETTA and MAISS evolution through the WWTP.

The other emulsifier isolated in particulate forms in the urban influent was MAISS. Imidazoline derivatives are a novel class of cationic surfactants, with a wide range of applications, mainly used as softeners and antistatic agents in fabrics, and as hair conditioning agents [24]. First used as dye levelling agents in the textile industry in the 1930s [25], their softening properties were discovered as a side effect [24]. Recent studies have proved ecotoxicological effects for imidazoline compounds, with a significant increase in DNA damage in the haemocytes and gills from adult mussels [26]. In our research, particulate forms (PF) containing MAISS displayed an average concentration of $0.36 \mathrm{PF} / \mathrm{L}$ in the influent and $0.14 / \mathrm{L}$ in the primary clarifier, totally disappearing in the biological reactor and final effluent of the WWTP. Fig. 4 depicts the evolution of particulate forms for both surfactants.

\subsubsection{Plasticizers}

Similarly, to heat stabilizers and surfactants, two different plasticizers were identified in particulate forms isolated in the urban wastewater; i.e., Butyl Ricinoleate (BR) and Di-obenzamido diphenyl disulfide (DBD).

As previously indicated for ETAA, the high cost of petrochemicals rapidly increased the interest in bio-based materials. So, the use of ricinoleic acid extracted from castor oil, with a further esterification, has influenced the behaviour of polymers, acting as plasticizers for PVC by reducing the glass transition of the polyesters and preventing crystallization even at very low temperatures [27], [28]. Besides for PVC, butyl ricinoleate is also an outstanding purpose plasticizer for other polymers; i.e., cellulose acetate, butyrate resins, nitrocellulose, and ethylcellulose. The presence of "dangling chains" in its constitution is the responsible for its action mechanism [28]. The average concentration of particulate forms including this additive in the WWTP was $0.43 \mathrm{PF} / \mathrm{L}$ in the influent, decreasing down to $0.14 \mathrm{PF} / \mathrm{L}$ in the primary clarifier and disappearing after that stage.

On the other hand, di-o-benzamido diphenyl disulfide (DBD) is used as a plasticizer or masticating agent for both natural and synthetic rubbers. In general, natural rubber supplied by plantations is too hard and not plastic enough to be used and mixed with rubber chemicals [29]. DBD is widely used in the latex industry, meeting the world demand for gloves, condoms, latex thread, etc. [30]. DBD particulate forms were only isolated in samples from 
the biological reactor, with an average value of $0.02 \mathrm{PF} / \mathrm{L}$, totally disappearing in the final effluent.

\subsection{Corrosion inhibitors}

Besides ETAA and MAISS, two emulsifiers also used as corrosion inhibitors in different industries [31], two other chemicals were present in particulate forms in the study; i.e., RTV730 and Molybdenum-Zinc Oxygen Complex (MZO Complex). The RTV-730 is a corrosion inhibitor and adhesive agent widely used, that cures at room temperature ("RTV" stands for Room Temperature Vulcanizing). It is a white material with a working temperature of 287$31{ }^{\circ} \mathrm{C}$ [32], used in the aviation industry. As a sealant, RTV-730 is resistant to halogenated hydrocarbons [33] and, in general, it is more resistant than other adhesives because it does not swell and lose adhesion [34]. In our study, this chemical only appeared in the influent, with an average concentration of $0.13 \mathrm{PF} / \mathrm{L}$.

MZO Complex, as other molybdenum-oxygen compounds, is added to steel and corrosion resistant alloys, and used in industrial catalysts, corrosion inhibitors, pigments, glass, ceramics, and enamels, but also as a flame retardant for polyester and PVC resins [35]. This compound improves the tribological properties of boundary-lubricated steel surfaces [36]. The presence of MZO Complex in this study was limited to the biological reactor, with an average concentration of $0.02 \mathrm{PF} / \mathrm{L}$.

\subsubsection{Other additives and chemicals of interest}

Many other interesting compounds were detected in particulate forms in the wastewater treatment plant; for instance, titanium dioxide $\left(\mathrm{TiO}_{2}\right)$. It is a white pigment with a high refractive index widely used in sunscreens and cosmetics [37] and in advanced oxidation processes [38], that remains attached to the microplastic after its manipulation [20]. Its potential risk has generated controversy with scientific papers reporting adverse effects [39] and others indicating lack of genotoxic potential both in vivo and in vitro [40]. Moreover, titanium dioxide has proved to have the ability to remove heavy metals from water [41].

In this study, particulate forms of $\mathrm{TiO}_{2}$ appeared in the influent, with an average concentration of $0.13 \mathrm{PF} / \mathrm{L}$, decreasing to a concentration of $0.02 \mathrm{PF} / \mathrm{L}$ in the biological reactor, and totally disappearing in effluent samples, as presented in Fig. 5.

Furthermore, two flame retardants or fire retardants were isolated as particulate forms in the effluent of WWTP; i.e., zinc borate and sodium antimonate. Although the most effective fire retardants additives in polymers are halogen-based materials, these compounds are known to be a source of corrosive, obscuring and toxic smoke during combustion [42]. As a solution, inorganic salts are added; zinc borate has been used as a flame retardant in the ethylene vinyl acetate copolymer formulation [43] with magnesium compounds, as well as for polyamides, in this case together with aluminium compounds, due to the formation of boron-aluminium phosphates that creates a fire protection barrier [44].

Zinc borate functions as a flame retardant, smoke and afterglow suppressant, and antitracking agent, and can partially replace antimony oxides in flexible PVC, not only reducing the peak rate of heat release, but also the carbon monoxide production [45].

Sodium antimonate is also used as a flame retardant with very low tinting characteristics, in plastics, paints, glass fibre resins and textile goods [46]. In our study, both flame retardants appeared as particulate forms in the effluent, in average concentrations of $0.01 \mathrm{PF} / \mathrm{L}$.

Another additive detected in particulate forms was Santoflex 13, used as a powerful antioxidant and antiozonant in pneumatic tyre components, providing protection against fatigue degradation [47], as well as in plants to offer foliar protection against ozone injury 


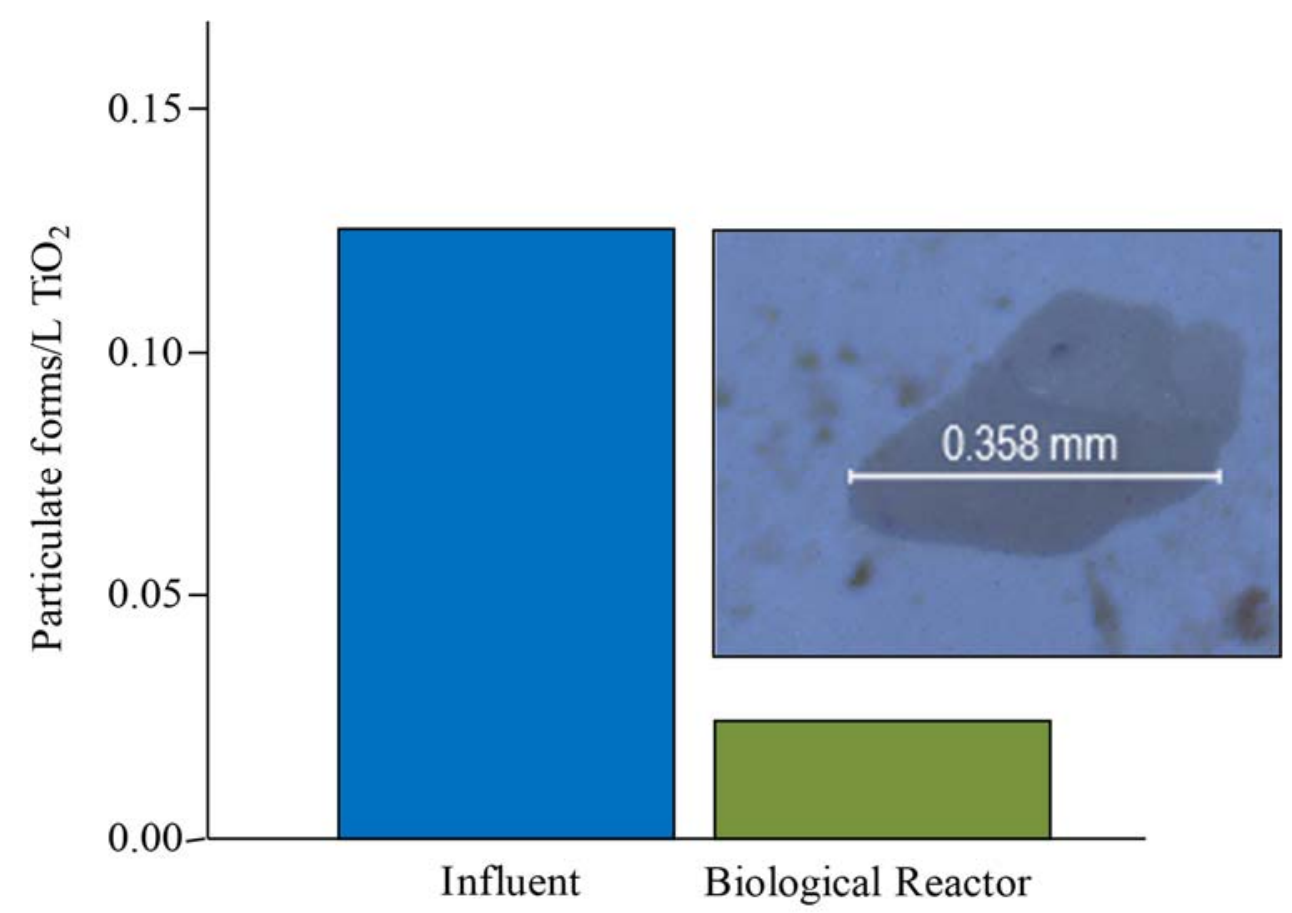

Figure 5: Titanium dioxide ( $\mathrm{TiO} 2)$ evolution through the wastewater treatment plant and particulate form containing this additive in the biological reactor of the WWTP (Library: Hummel Polymer and Additives).

[48]. These particulate forms containing Santoflex 13 appeared only in the influent of the WWTP, with an average concentration of $0.14 \mathrm{PF} / \mathrm{L}$.

Montan Ester Wax (MEW), a light stabilizer and textile auxiliary [49] is a mixture of chemical compounds, developed for manufacturing dry-bright floor polishes for both household and industrial use, car and shoe polishes, paints, and as a lubricant for moulding plastics [50]. This additive was isolated in particulate forms from the influent $(0.13 \mathrm{PF} / \mathrm{L})$, with a distinct decrease for the biological reactor $(0.02 \mathrm{PF} / \mathrm{L})$, disappearing after.

Finally, the bactericide 2-Methyl-1,2-benzisothiazol-3(2H)-one (MBI) was also found in some particulate forms of the effluent, with an average concentration of $0.03 \mathrm{PF} / \mathrm{L}$. It is commonly used in antimicrobial formulations for products such as paints, plasters, adhesives or household products [51]. Fig. 6 depicts some of these other additives contained in particulate forms.

\section{CONCLUSIONS}

This paper deals with the role of WWTP as a sink and source of additives associated to microplastics particulate forms. The monitoring study was carried out during September 2016 and October 2017, with $9.0 \%$ of particulate fraction as a major source of plastic additives, such as antioxidants, lubricants, antimicrobials, plasticizers, adhesives, heat stabilizers or flame retardants, among others, taking into account that plastics may contain 

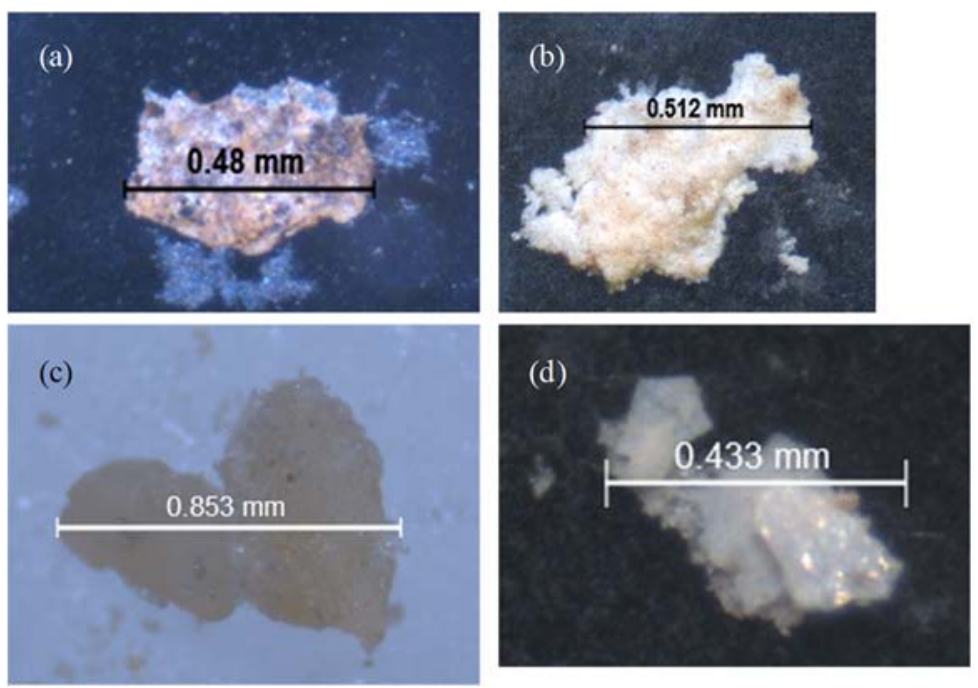

Figure 6: Particulate forms containing the additives. (a) Zinc borate in the effluent; (b) Sodium antimonate in the effluent; (c) Montan Ester Wax (MEW) in the biological reactor; and (d) MBI in the effluent of the WWTP (Libraries: Polymer Additives and Plasticizers for (a)-(c); and Hummel Polymer and Additives for (d).

up to $4 \%$ of their weight as additives. It is well known that these additives can leak out during the life cycle of the product, being potentially harmful to wildlife. Our results indicated a statistically significant decrease of all these chemicals through the WWTP, accounting for a $91.2 \%$. The main plastic additives associated to particulate forms isolated in this research were heat stabilizers Zn/Ca soap and, Methyl Tin Mercaptide (MTM), referenced as the most common PVC stabilizers used all over the world, whose concentrations proved to be statistically correlated, and with removal rates of $85.2 \%$ and $89.2 \%$, respectively. Ethoxylated Tallow Alkyl Amine (ETAA), and Methyl Alkyl Imidazoline Sodium Salts (MAISS) also were detected in particulate forms located in samples from the influent, primary clarifier, and biological reactor. They are two emulsifiers, non-ionic and cationic, respectively, with a wide range of applications that proved to disappear in the final effluent. Plasticizers Butyl Ricinoleate (BR), and Di-o-benzamido diphenyl disulfide (DBD) were also present in wastewater samples, being removed before the final discharge. Corrosion inhibitors; i.e., RTV-730, and Molybdenum-Zinc Oxygen Complex (MZO Complex); and other additives as titanium dioxide, the fire retardants Zinc Borate and Sodium Antimonate, antioxidant Santoflex, or the light stabilizer Montan Ester Wax (MEW) appeared in the WWTP in lower concentrations.

\section{ACKNOWLEDGEMENTS}

Analyses carried out by S. Olmos were supported by a UPCT fellowship (B-094/17 - Project 30.05.21.7312). The authors would like to extend their thanks to crew from wastewater treatment plant of Cartagena for their assistance with sample collection. 


\section{REFERENCES}

[1] Plastics - the Facts 2017. An analysis of European plastics production, demand and waste data. www.plasticseurope.org/download_file/view/477/179. Accessed on: 7 Feb. 2018.

[2] Ruzette, A.V. \& Leibler, L., Block copolymers in tomorrow's plastics. Nature Materials, 4(1), pp. 19-31, 2005.

[3] Pires, A., Martinho, G., Ribeiro, R., Mota, M. \& Teixeira, L., Extended producer responsibility: a differential fee model for promoting sustainable packaging. Journal of Cleaner Production, 108, pp. 343-353, 2015.

[4] Bayo, J., Guillén, M., Olmos, S., Jiménez, P., Sánchez, E. \& Roca, M.J., Microplastics as vector for persistent organic pollutants in urban effluents: The role of polychlorinated biphenyls. International Journal of Sustainable Development and Planning, 13(4), pp. 671-682, 2018.

[5] Bayo, J., Olmos, S., López-Castellanos, J. \& Alcolea, A., Microplastics and microfibers in the sludge of a municipal wastewater treatment plant. International Journal of Sustainable Development and Planning, 11(5), pp. 812-821, 2016.

[6] Estahbanati, S. \& Fahrenfeld, N.L., Influence of wastewater treatment plant discharges on microplastic concentrations in surface water. Chemosphere, 162, pp. 277-284, 2016.

[7] Andrady, A.L. \& Neal, M.A., Applications and societal benefits of plastics. Philosophical Transactions of the Royal Society B: Biological Sciences, 364, pp. 1977-1984, 2009.

[8] Lithner, D., Damberg, J., Dave, G. \& Larsson, A., Leachates from plastic consumer products - Screening for toxicity with Daphnia magna. Chemosphere, 74, pp. 11951200, 2009.

[9] Fang, L., Song, Y., Zhu, X. \& Zheng, Q., Influence of lanthanum stearate as a costabilizer on stabilization efficiency of calcium/zinc stabilizers to polyvinyl chloride. Polymer Degradation and Stability, 94, pp. 845-850, 2009.

[10] VINYL PLUS. www.vinylplus.eu.

[11] Thomas, N.L., Calcium/zinc stabilizers for PVC pressure pipe. Plastics, Rubber and Composites Processing and Applications (UK), 19(5), pp. 263-271, 1993.

[12] Lida, T., Kataoka, N., Ueki, N. \& Goto, K., Stabilization of poly (vinyl chloride). III. Synergism between metal soaps and masking agents on the stabilization of poly (vinyl chloride). Journal of Applied Polymer Science, 21(8), pp. 2041-2050, 1977.

[13] Fu, Q.Q., Chen, M. \& Yang, J.D., Analysis on a case of acute methyltin mercaptide poisoning accident in a plastic company. China Occupational Medicine, 3, p. 40, 2008.

[14] Quevauviller, P., Lavigne, R., Pinel, R. \& Astruc, M., Organo-tins in sediments and mussels from the Sado estuarine system (Portugal). Environmental Pollution, 57(2), pp. 149-166, 1989.

[15] Nikolaou, A.D., Gatidou, G.M., Golfinopoulos, S.K., Thomaidis, N. \& Lekkas, T.D., A one-year survey of organotin compounds in the reservoirs supplying the drinking water treatment plants of Athens, Greece. Desalination, 210(1)-(3), pp. 24-30, 2007.

[16] Wang, X. et al., Process optimization for treatment of methyltin mercaptide effluents using modified semi-coke. Journal of Central South University, 20(12), pp. 36333640, 2013.

[17] Liu, P. et al., Hydroxylbenzylthioethers as novel organic thermal stabilizers for rigid PVC. Polymer Degradation and Stability, 92(3), pp. 503-508, 2007. 
[18] Chaochanchaikul, K., Rosarpitak, V. \& Sombatsompop, N., Structural and thermal stabilizations of PVC and wood/PVC composites by metal stearates and organotin. BioResources, 6(3), pp. 3115-3131, 2011.

[19] Bayo, J., Esteban, G. \& Castillo, J., The use of native and protonated grapefruit biomass (Citrus paradisi L.) for cadmium (II) biosorption: equilibrium and kinetic modelling. Environmental Technology, 33(7), pp. 761-772, 2012.

[20] Bayo, J., Martínez, A., Guillén, M., Olmos, S., Roca, M.J. \& Alcolea, A., Microbeads in commercial facial cleansers: threatening the environment. CLEAN - Soil, Air, Water, 45(7), pp. 1-11, 2017.

[21] Hampton, C., Demoin, D. \& Glaser, R.E. (ed.), Vibrational spectroscopy tutorial: sulfur and phosphorus. Organic Spectroscopy, 2010.

[22] Maag, H., Fatty acid derivatives: important surfactants for household, cosmetic and industrial purposes. Journal of the American Oil Chemists' Society, 61(2), pp. 259267, 1984.

[23] Gauvrit, C., Glyphosate response to calcium, ethoxylated amine surfactant, and ammonium sulfate. Weed Technology, 17(4), pp. 799-804, 2003.

[24] Tyagi, R., Tyagi, V.K. \& Pandey, S.K., Imidazoline and its derivatives: an overview. Journal of Oleo Science, 56(5), pp. 211-222, 2007.

[25] Levinson, M.I., Rinse-added fabric softener technology at the close of the twentieth century. Journal of Surfactants and Detergents, 2(2), pp. 223-235, 1999.

[26] Alharbi, O.M., Biomarker assessment of the ecotoxicological impact of environmental concentrations of oilfield corrosion inhibitors and produced water. Doctoral dissertation, Heriot-Watt University, 2013.

[27] Frankel, E.N., Neff, W.E., Thomas, F.L., Khoe, T.H., Pryde, E.H. \& Riser, G.R., Acyl esters from oxo-derived hydroxymethylstearates as plasticizers for polyvinyl chloride. Journal of the American Oil Chemists Society, 52(12), pp. 498-504, 1975.

[28] Petrović, Z.S. et al., Polyester polyols and polyurethanes from ricinoleic acid. Journal of Applied Polymer Science, 108(2), pp. 1184-1190, 2008.

[29] Früh, T., Heiliger, L. \& Müller, G.E., Use of dialkyl polysulfides for mastication of natural and synthetic rubbers. U.S. Patent No 7,135,515, 2006.

[30] Rajan, V.V., Dierkes, W.K., Joseph, R. \& Noordermeer, J.W., Effect of diphenyldisulfides with different substituents on the reclamation of NR based latex products. Journal of Applied Polymer Science, 104(6), pp. 3562-3580, 2007.

[31] Zhang, K., Xu, B., Yang, W., Yin, X., Liu, Y. \& Chen, Y., Halogen-substituted imidazoline derivatives as corrosion inhibitors for mild steel in hydrochloric acid solution. Corrosion Science, 90, pp. 284-295, 2015.

[32] Browne, G.T., US Naval air force avionic and electrical system corrosion prevention and control maintenance. Naval Air Force (Atlantic) Norfolk, VA, 1987.

[33] Nguyen, T.Q. \& Nobe, K., Extraction of organic contaminants in aqueous solutions by pervaporation. Journal of Membrane Science, 30(1), pp. 11-22, 1987.

[34] Hoover, K.C. \& Hwang, S.T., Pervaporation by a continuous membrane column. Journal of Membrane Science, 10(2-3), pp. 253-271, 1982.

[35] Vukasovich, M.S. \& Farr, P.G., Molybdate in corrosion inhibition - A review. Polyhedron, 5(1-2), pp. 551-559, 1986.

[36] Komvopoulos, K., Pernama, S.A., Yamaguchi, E.S. \& Ryason, P.R., Friction reduction and antiwear capacity of engine oil blends containing zinc dialkyl dithiophosphate and molybdenum-complex additives. Tribology Transactions, 49(2), pp. 151-165, 2006. 
[37] López Paraguay, M.Z., Cortes, J.A., Pérez-Robles, J.F. \& Alarcón-Herrera, M.T., Adsorption of arsenite from groundwater using titanium dioxide. CLEAN-Soil, Air, Water, 42(6), pp. 713-721, 2014.

[38] Caliman, F.A. \& Gavrilescu, M., Pharmaceuticals, personal care products and endocrine disrupting agents in the environment - a review. CLEAN-Soil, Air, Water, 37(4-5), pp. 277-303, 2009.

[39] Mansfield, C.M. et al., Photo-induced toxicity of titanium dioxide nanoparticles to Daphnia magna under natural sunlight. Chemosphere, 120, pp. 206-210, 2015.

[40] Landsiedel, R. et al., Gene toxicity studies on titanium dioxide and zinc oxide nanomaterials used for UV-protection in cosmetic formulations. Nanotoxicology, 4(4), pp. 364-381, 2010.

[41] Mohan, D. \& Pittman Jr, C.U., Arsenic removal from water/wastewater using adsorbents - A critical review. Journal of Hazardous Materials, 142(1-2), pp. 1-53, 2007.

[42] Zaikov, G.E., Recent advances in flame retardancy of polymeric materials. International Journal of Polymeric Materials, 36(1-2), pp. 33-38, 1997.

[43] Carpentier, F., Bourbigot, S., Le Bras, M., Delobel, R. \& Foulon, M., Charring of fire retarded ethylene vinyl acetate copolymer-magnesium hydroxide/zinc borate formulations. Polymer Degradation and Stability, 69(1), pp. 83-92, 2000.

[44] Braun, U., Schartel, B., Fichera, M.A. \& Jäger, C., Flame retardancy mechanisms of aluminium phosphinate in combination with melamine polyphosphate and zinc borate in glass-fibre reinforced polyamide 6,6. Polymer Degradation and Stability, 92(8), pp. 1528-1545, 2007.

[45] Shen, K.K., Kochesfahani, S. \& Jouffret, F., Zinc borates as multifunctional polymer additives. Polymers for Advanced Technologies, 19(6), pp. 469-474, 2008.

[46] Anderson, C.G., The metallurgy of antimony. Chemie der Erde-Geochemistry, 72, pp. 3-8, 2012.

[47] Ushmarin, N.F. \& Kavun, S.M., New antiozonants for rubber compounds based on oxyalkylated derivatives of 4-aminodiphenylamine. International Polymer Science and Technology, 44(11), pp. 29-35, 2017.

[48] Gilbert, M.D., Elfving, D.C. \& Lisk, D.J., Protection of plants against ozone injury using the antiozonant $\mathrm{N}-(1,3$-dimethylbutyl)-N'-phenyl-p-phenylenediamine. Bulletin of Environmental Contamination and Toxicology, 18(6), pp. 783-786, 1977.

[49] Hummel, D.O., Atlas of Plastics Additives: Analysis by Spectrometric Methods, Springer Science \& Business Media: Berlin and New York, 2012.

[50] Montanwachs, V., Natural montan wax and its raffinates. European Journal of Lipid Science and Technology, 103, pp. 239-248, 2001.

[51] Wypych, G. \& Wypych, A., Databook of Preservatives, Elsevier: Toronto, 2015. 